\title{
Medical education units: A necessity for quality assurance in health professions education in Nigeria
}

\author{
A O Adefuye, ${ }^{1}$ MB ChB, MSc, PhD (Med); H A Adeola ${ }^{2,3}$ DDS, PhD (Med); J Bezuidenhout, ${ }^{1}$ BA (Ed), MEd, DTech (Ed), PGD (HPE) \\ ${ }^{1}$ Division of Health Sciences Education, Office of the Dean, Faculty of Health Sciences, University of the Free State, Bloemfontein, South Africa \\ ${ }^{2}$ Department of Oral and Maxillofacial Pathology, Faculty of Dentistry, University of the Western Cape, Cape Town, South Africa, and Tygerberg Hospital, Cape Town, South Africa \\ ${ }^{3}$ Division of Dermatology, Department of Medicine, Faculty of Health Sciences, University of Cape Town, and Groote Schuur Hospital, South Africa
}

Corresponding author: A O Adefuye (AdefuyeAO@ufs.ac.za)

\begin{abstract}
In recent years, curricula and pedagogical methods in medical education have undergone rapid and unprecedented changes globally. The emphasis has shifted from traditional, teacher-centred learning, characterised by the accumulation of non-integrated volumes of knowledge, to active, student-centred learning. The Medical and Dental Council of Nigeria (MDCN) reports that there are 31 fully accredited and 6 partially accredited medical schools in Nigeria. The majority of these medical schools still offer undergraduate medical training based on a curriculum characterised by a distinct separation of preclinical and clinical training, with minimal or no integration. This approach is coupled with low-quality teaching by medical educators, as many medical colleges in Nigeria presently use specialists as lecturers who have little or no training in higher education practices; their only exposure to teaching is that obtained during their postgraduate specialty training. Similarly, very few medical schools in Nigeria have established medical education units (MEUs), as recommended by the World Health Organization and the World Federation for Medical Education. We discuss the shortcomings of the present medical education system in Nigeria and suggest ways to improve the quality of pedagogy among Nigerian medical educators, such as the establishment of clinical-skills centres and MEUs at Nigerian medical schools. In addition, this review highlights the role and importance of MEUs in facilitating quality assurance in health professions education, and the urgent need for more medical schools in Nigeria to establish MEUs to promote, co-ordinate and evaluate medical education reforms based on needs assessments and within the confines of MDCN standards.
\end{abstract}

Afr J Health Professions Educ 2018;10(1):5-9. DOI:10.7196/AJHPE.2018.v10i1.966

As reported in the Edinburgh Declaration on Medical Education of $1988,{ }^{[1]}$ the main goal of any medical education programme is to produce clinicians who will promote the health and well-being of all people adequately, and not merely deliver curative medical services. Therefore, quality assurance in health professions education and social accountability should be part of every country's ethical responsibility. ${ }^{[2]}$ Physicians graduating from medical colleges must be competent clinicians, clinical thinkers, critical thinkers, self-directed learners, team players, effective communicators, problemsolvers and collaborators if they are to provide high-quality medical care within clearly defined criteria of minimally accepted standards. ${ }^{[3]}$

However, many middle- to low-income nations, including Nigeria, have failed to achieve this goal, and are not aligned with the enormous advances in biomedical sciences that are taking place elsewhere. Of great concern is the claim that graduates of medical colleges in Nigeria who trained under the present curriculum may lack the skills and aptitude required for success in the changing practice environment of the 21 st century. ${ }^{[4]}$ In response, the Nigerian Federal Ministry of Health, in conjunction with the Medical and Dental Council of Nigeria (MDCN) and the National University Commission (NUC) have, on several occasions, set up committees in an attempt to review the medical and dental education curricula in the country. ${ }^{[4]}$ This has, however, not yielded any favourable results. ${ }^{[5,6]}$ The failure of these committees/meetings therefore necessitates a new approach to improving the quality of medical education in Nigeria. There is an urgent need to pay particular attention to matters of medical education and educator training.

\section{Medical practice and medical education in Nigeria}

The MDCN remains the main regulatory body for medical and dental practice in Nigeria. It was established by the Medical and Dental Practitioners' Act of 28 June 1988 (CAP M8 LFN 2004) to replace the Nigerian Medical Council established by the Medical and Dental Practitioners' Act of 18 December 1963. ${ }^{[7]}$ The mandates of the MDCN are to regulate training and practices in medicine, dentistry and alternative medicine in Nigeria; determine the knowledge and skills of health professionals; and to regulate and control laboratory medicine in Nigeria. ${ }^{[7]}$ While the various universities/colleges of health sciences are at liberty to establish academic/medical education programmes at undergraduate level, the MDCN remains the only authority empowered to approve courses, institutions and qualifications intended for persons seeking to be registered as health professionals.

\section{Medical curricula and pedagogical methods of medical education in Nigeria}

According to the MDCN, there are 31 fully accredited and 6 partially accredited medical schools in Nigeria. Nine of the 31 fully accredited Nigerian medical schools have dental schools, of which 7 are fully accredited and 2 have partial accreditation. While the development of medical curricula remains the sole responsibility of the senates of the individual universities, the MDCN and the NUC are mandated to determine the minimum standards of these curricula. Historically, the MDCN and NUC employ dissimilar approaches to medical education, owing to differences in 
their targets and priorities. These contrasting interests, as presented below of the dual monitoring bodies for medical education in Nigeria present a dilemma (Table 1).

The expected learning activities during a programme of study or a course that results in the acquisition of knowledge and skills is known as a curriculum. ${ }^{[9]}$ Some of the capacities enabled by the design of a curriculum include determining professional and educational context for programme development and delivery; aligning the needs of learners and the expectations of professional bodies; determining learning outcomes; recognising constraints; determining the areas of learning and teaching; reviewing the modules based on feedback; and determining the topic sequence and key examinations. ${ }^{[9]}$ Over the years, emphasis and trends in planning and design of the medical curriculum and pedagogical methods in medical education have shifted, from traditional passive (teacher-centred) learning, characterised by the accumulation of non-integrated volumes of knowledge, to an active (self-directed/student-centred), systematic approach. ${ }^{[10-13]}$

Though Nigeria is the most populous nation in Africa and has four generations of medical schools, not much has changed in the blueprint of the medical education curriculum since the inception of the first medical school in $1948 .{ }^{[5]}$ There has not been any systematic training pathway for medical educators; nor has there been significant curriculum review or planning. Although, on paper, regulatory bodies such as the NUC and MDCN have proposed modifications of the traditional medical education curriculum in line with regional and global standards, there has been a varying degree of response towards medical curriculum review. ${ }^{[5]}$ The Federal Ministry of Health of Nigeria, supported by the United States Agency for International Development (USAID), under the flagship of the Health 20/20 project, developed the Nigeria Undergraduate Medical and Dental Curriculum Template, 2012, from which individual schools could develop their own curriculum de novo. ${ }^{[14]}$ This curriculum template boasts being a home-grown, needs-assessment-based, integrated, systembased, person-centred, community-oriented and competency-driven model, meant to provide medical students with the best possible learning opportunities and to produce competent medical graduates. Major revision of medical/dental curricula is recommended every 5 years, owing to the diminishing lifespan of useful medical information and the increasing complexity of medical practice. ${ }^{[15]}$ Reviewing a medical curriculum is a complex process that involves human, capital and time resources. ${ }^{[16]}$ For example, the revision of the traditional Bachelor of Medicine and Bachelor of Surgery (MBBS) curriculum to a competency-based curriculum (CBME; competency-based medical education) at the College of Medicine, University of Ibadan, took approximately 12 years (2001 - 2012), in a series of overlapping processes. ${ }^{[15]}$ Few medical colleges in Nigeria have access to the necessary resources (human, capital and time), which causes curriculum stagnation. ${ }^{[6]}$

The current medical education curriculum in use at most medical colleges in Nigeria involves 2 and 4 years of preclinical and clinical training, respectively. Each of these stages is followed by an examination in the form of written, practical/clinical and oral (viva voce) exams. Some medical schools have introduced objective structured clinical exams or objective structured practical exams into their student assessment, which improve objective evaluation of students, compared to long and short cases methods of assessment. There is a lack of integration between the preclinical and clinical curricula in most medical schools, making it difficult to harness the skills and experience acquired at both levels of training. ${ }^{[5]}$ This lack of integration is exacerbated by the fact that the medical educators are specialists with little or no training in higher education practices, ${ }^{[17]}$ and whose only exposure to teaching is that obtained during their postgraduate training. ${ }^{[6]}$ Most lecturers lack training in modern educational methods, and therefore cannot improve their teaching output, leading to poor student outcomes. ${ }^{[6]}$ There is therefore an urgent need for compliance with global shifts in medical curricula, in order to improve the training and evaluation of medical doctors and dentists in Nigeria.

\section{Shortfalls of the present system and suggested solutions}

The shortfalls of the present medical education system in Nigeria are outlined below.

(i) Medical curricula and pedagogical methods: These still follow an opportunistic approach, leading to curriculum overload and atrophy. ${ }^{[15]}$

(ii) Staff quality: This is not optimal, and there is a paucity of systematic training programmes for medical educators. The only requirement of the current system is that doctors who train medical students possess medical specialist qualifications, irrespective of whether these educators are wellequipped or even willing to train undergraduates.

(iii) Quality of medical doctors: This is not consistent, owing to the lack of standards vis-à-vis medical curriculum approval and medical school accreditation, and the quality of medical doctors produced by the different medical schools. ${ }^{[5]}$ Institutions in the medical sector lack adequate and modern learning and evaluation facilities. ${ }^{[6]}$

(iv) Unreliable forms of assessment: The viva voce examination has been used subjectively as a victimisation tool to punish students perceived to be disrespectful to their teachers. ${ }^{[18]}$ Furthermore, oral examinations have been demonstrated to have low reliability as an assessment tool for clinical competence. ${ }^{[19]}$ Another inconsistency relates to the fact that some examiners are generous when marking oral exams, while others are not. ${ }^{[19]}$ Although it

Table 1. Contrasting interests of the dual monitoring bodies for medical education in Nigeria

National University Commission (NUC)

Prefers a course credit system and wants all medical teachers to be in possession of a $\mathrm{PhD}$ before promotion into senior academic positions. Would like to grow the quota intake of medical students per year.

Prescribes minimum academic standards, and ensures, through periodic monitoring, that training institutions adhere to these minimum standards.

\section{Medical and Dental Council of Nigeria (MDCN)}

Does not support these requirements. ${ }^{[6]}$

Wishes to ensure that the available facilities are able to accommodate such increases without compromising the quality of graduating doctors. ${ }^{[6]}$

Minimum requirements have been set by the MDCN in terms of student intake, minimum physical facilities, learning resources, administrative facilities and teaching staff requirements. ${ }^{[8]}$ 
has been postulated that the use of long case/short case as a form of assessment appears to be suitable for situations where resources are limited, ${ }^{[14]}$ its subjectivity makes it highly unreliable as an assessment tool. Considering that professional development progress depends on a grounded relationship between continued educational activity and performance, a practical framework that could be used for evaluating competencies/skills at Nigerian medical schools is Miller's Pyramid, which employs multilevel achievement steps, starting with knowledge at the bottom and ending with competence at the top. ${ }^{[20]}$

To tackle these problems, renewed efforts should be made to achieve greater synergy between the NUC and MDCN, medical educators should be mandated to undergo training in educational methods, and more medical colleges in the country should be supported to undertake curriculum reviews that reflect modern trends in medical education.

\section{The need for medical education units at medical schools in Nigeria}

The Cape Town Declaration of 1995, which was the outcome of the African Regional Conference of the World Health Organization and the World Federation for Medical Education, states that medical (health sciences) education units (MEUs) should be established at every medical school, and that mechanisms should be put in place for promoting, co-ordinating and evaluating medical education reforms. Since then, independent MEUs or similar bodies have been established at medical schools across the African continent. ${ }^{[21,22]}$ Titles commonly given to these units include office, division, department, centre and unit. ${ }^{[23]}$ However, very few medical schools in Nigeria have established MEUs. ${ }^{[2]}$ This deficiency is evident from a 2007 study carried out by Ofeogbu and Ozumba, ${ }^{[2]]}$ which surveyed 26 accredited medical schools in Nigeria to determine whether they had independent MEUs. Of the 14 respondents, only 1 had a designated MEU. By 2017, the number of accredited medical schools in Nigeria had grown to 31 fully accredited medical and 7 dental schools. ${ }^{[7]}$ However, a comprehensive online literature search for 'medical education department or health science education unit or office or centre or division' at medical schools in Nigeria, undertaken in the course of this review, revealed that only two medical schools, the College of Medicine, University of Nigeria, Enugu ${ }^{[21]}$ and the College of Medicine, University of Ibadan, Nigeria, ${ }^{[24]}$ have established MEUs.

The activities of MEUs transcend educational levels, and encompass undergraduate, postgraduate and continuing medical education. ${ }^{[25]}$ The roles of MEUs include teaching, programme evaluation, facilitating the use of educational technologies, planning, implementing and promoting educational (teaching and learning) development and supporting medical education research. ${ }^{[26]}$ It has been suggested that establishing MEUs at medical schools in Nigeria will be a good starting point to stimulate strategy for curriculum transformation in order to improve the quality of health professions education. ${ }^{[24]}$ On the basis of needs assessment, MEUs at individual medical schools can determine their training needs through constant curriculum reform and evaluation processes within the specified standards of the MDCN. ${ }^{[27]}$

The purpose of medical education at all levels is to prepare knowledgeable and highly skilled healthcare professionals taxed with delivering safe and effective patient care. ${ }^{[28]}$ The traditional learning model of medical education is undergoing a pedagogical shift, to a simulation-based medical education (SBME) learning model. ${ }^{[28]}$ Not all medical educators in Nigeria are aware of the minimum standards for teaching and learning at both undergraduate and postgraduate levels, including educational technologies that can be utilised. ${ }^{[29]}$ SBME is an effective pedagogical tool that can be used to develop new skills, identify knowledge gaps, reduce medical errors and maintain infrequently used clinical skills, even among experienced clinical teams, with the overall goal of improving patient care ${ }^{[28]}$ Planning and establishing a simulation/clinical-skill centre that can train staff on the basic pedagogical principles of SBME and deliver it effectively will be the core role of the professional team situated at an MEU. However, the human, time and, particularly, the financial resources required to set up a dedicated simulation/clinical-skill centre might prove to be a challenge for most medical colleges in Nigeria. Nevertheless, overcoming these challenges will yield a rich return. In the area of research, MEUs can support health professionals/medical educators to conduct research in the field of medical education in their respective fields of practice. ${ }^{[30]}$

\section{Steps toward establishing MEUs in Nigeria}

Taking into consideration the variability in culture, geographical location and available resources, approaches to setting up MEUs at individual medical colleges across Nigeria may vary considerably. However, we suggest key steps and methods for setting up successful MEUs at medical schools in Nigeria. ${ }^{[29]}$

(i) Conduct a needs assessment: The opinions of the various stakeholders in medical education (college executives, teaching and non-teaching staff, medical/dental students, employers of doctors and members of the public) of the individual medical college should be sought. The needs assessment could probe into the kind of health professionals (doctors, dentists, nurses or physiotherapists, for instance) needed by modern medical practice, the curricula required to produce the desired health professionals, the pedagogical methods in which the curriculum will be presented and the support needed to improve the quality of pedagogy among medical educators.

(ii) Solicit appropriate administrative support: In the academic environment, establishing a new unit/division such as an MEU would generally require a great deal of administrative support from the dean and other powerful advocates within the medical school, such as the faculty management/board and university senate committee. Approaching a newly appointed dean for support might yield a positive result, as studies have shown that newly appointed organisational heads are keen to effect organisational change, and are receptive to implementing new innovations. ${ }^{[31]}$ Lobbying for a dean's support may involve presenting the results of the needs assessment study that justifies the establishment of an MEU, and making the necessary recommendations. Data can be gathered through questionnaire surveys, interviews (semi-structured or structured), focus group discussions, nominal group discussions and an expert Delphi survey, to attain consensus on salient topics. A thorough review of the existing literature, discussing the current strengths and weaknesses of current medical education systems and demonstrating practical ways in which establishing an MEU will benefit a department, could also be part of the needs assessment process. Recommendations should be made and reports produced on the way in which an established MEU can help attain anticipated goals, namely enhancing curriculum reform, improving staff skills regarding medical education and producing exceptional medical graduates who will meet the needs of society. 
(iii) Nominate a technical working group (TWG): Nominating a TWG that will be taxed with working on various aspects of the project will be essential at the onset. Members of the TWG may include academic staff from the various departments within the faculty, and an education expert.

(iv) Train staff and build capacity: Several members of the TWG may need to undertake formal training in medical education, both locally and internationally. Training could take the form of visits to other institutions with established MEUs, both locally and internationally. Such visits will enable networking that can lead to personnel development, academic stimulation, mutual support and practical demonstrations of what should be done and how it can be done. ${ }^{[29]}$

(v) Conduct preliminary discussions with relevant regulatory bodies: These discussions on the role an MEU will play in the medical education arena, e.g. health professions education, staff development and research should be held with the MDCN and the NUC.

(vi) Staff the MEU: The staff size and staff profile of an MEU will vary according to the unit's roles in each institution. ${ }^{[26]}$ On average, MEUs employ five or more academic staff with professional qualifications such as a $\mathrm{PhD}$ DEd or MBBS/MB ChB and three or more support/administrative staff. ${ }^{[30]}$

(vii) Obtain a mandate for funding for a few years before becoming selfsupporting: This mandate should be obtained from the governing body of the institution. ${ }^{[29]}$

(viii) Attract financial resources: Resources could be obtained through grant incomes that can be used to support the activities of the unit, which could include multicentre research on medical education.

(ix) Establish networks with other MEUs: These networks should be established both nationally and internationally.

(x) Ensure a non-judgemental approach to members of the faculty: Creating a supportive, encouraging and facilitating approach will ensure acceptance of the newly created MEU. ${ }^{[29]}$

\section{Factors hindering the establishment of MEUs at medical schools in Nigeria, and suggestions for solutions}

The challenges hindering the establishing medical education units at medical at medical schools in Nigerian are summarised below.

(i) Financial hurdles: To create MEUs of uniform standard, quality and efficacy at Nigerian medical schools, the co-operation of the government, university, hospitals and private and international organisations to support the project financially is very important. Public-private support partnerships could be established by medical school authorities to reduce the financial burden of setting up and staffing an MEU. In addition, the financial burden can be defrayed by innovation and by improvising with resources already available at the respective medical schools. For example, mobile devices and newly emerging apps can be used for the dissemination of information to healthcare professionals, and for training medical educators and students. ${ }^{[32]}$ As explained by Ofoegbu and Ozomba, ${ }^{[21]}$ existing faculty members could be allowed to spend a percentage of their working time as ad hoc staff in the MEU. Because financial hurdles can constitute an impediment to setting up an MEU, the judicious use of existing resources is key.

(ii) MDCN and NUC bureaucracy: A practical suggestion for overcoming NUC and MDCN bureaucracy is to establish a mutually agreed-upon minimum requirement for medical education and medical educators in Nigeria. A major contributing factor to the lack of progress in this regard is the dearth of qualified medical educators with appropriate training and qualifications in medical education. The dual authority of the NUC and MDCN should be actively directed towards establishing health professionals' education units across the country. As it is sometimes the same individuals who perform accreditation for both MDCN and NUC, ${ }^{[6]}$ these individuals should carry out these duties in a manner that harmonises the mandates of the two bodies.

(iii) Lack of willingness to change: Medical educators are sometimes sceptical of the drastic changes that a revision of the curriculum by MEUs might cause, and fear that such changes would erode their busy clinical schedules. If this scepticism is prevalent at a medical school, the leadership of the school could engage MEU advocates to systematically engage faculty members on the benefits of having an independent MEU at the university.

(iv) Sustainability: Once an MEU has been established, its success depends on the willingness of the institution and faculty members to sustain its existence and efficacy. ${ }^{[21]}$ An independent evaluation of the efficacy of the MEU must be carried out periodically, possibly by the MDCN and/or NUC, and each MEU must strive to achieve excellence.

(v) Leadership: To establish lasting reform in medical education via MEUs, a strong leadership structure is an essential requirement. ${ }^{[26]}$ MEUs should be directed by leaders who are good role models and are able to motivate members of the MEU. In addition, such leaders should be visionaries, and remain professionally aligned to the development initiative of the MEU of the medical school. They should also be able to create good mentorship and collaborative research networks across the medical school.

(vi) Research and service focus: MEUs should not only be dedicated to providing medical education services to the medical community, but also be constantly engaged in research. ${ }^{[26]} \mathrm{A}$ lack of research by an MEU could result in diminished innovation, and lead to the complete loss of its function.

\section{Conclusion}

This review highlights the role of and importance of MEUs in facilitating quality assurance in health professions education, and the urgent need for more medical schools across Nigeria to establish such MEUs to promote, co-ordinate and evaluate medical education reforms on the basis of needs assessment, and within the confines of MDCN standards. Medical curriculum and course design must be built on the premises of modern-day educational theories; this would promote the production of a communityoriented and competent health workforce, ${ }^{[33]}$ and expand the learning and teaching experience of both the student and the medical teacher. Medical curricula should be designed to accommodate dynamic learning and teaching strategies, to produce customised medical practitioners who can maximise the resources available in order to serve in their own local environments. ${ }^{[33]}$

\section{Acknowledgements. None}

Author contributions. AOA conceptualised, designed, prepared and critically revised the manuscript, and HAA and JB were involved in the design and critical intellectual revision of the article. All authors read and approved the final manuscript submitted for publication.

Funding. The Health and Welfare Sector Education and Training Authority (HWSETA), SA.

Conflicts of interest. None.

1. Walton HJ. Edinburgh declaration and medical education. Lancet 1989;333(8629):105. https://doi.org/10.1016 S0140-6736(89)91466-9 


\section{Forum}

2. Woollard RF. Caring for a common future: Medical schools' social accountability. Med Educ 2006;40(4):301-313 https://doi.org/10.1111/j.1365-2929.2006.02416.x

. Boelen C. Building a socially accountable health professions school: Towards unity for health. Educ Healt 2004;17(2):223-231. https://doi.org/10.1080/13576280410001711049

. Olasoji HO. Rethinking the approach to curriculum review in medical and dental education in Nigeria. J Educ Pract 2014;5(32):82-87. https://pdfs.semanticscholar.org/2d85/83f69aa6e7a54702578d22c87a2223d4a7f9.pdf (accessed 2 February 2017)

5. Ibrahim M. Medical education in Nigeria. Med Teach 2007;29(9-10):901-905. https://doi org $/ 10.1080 / 01421590701832130$

6. Malu A. Universities and medical education in Nigeria. Niger Med J 2010;51(2):84-88. http://www.nigeriamedj. com/textasp?2010/51/2/84/71004 (accessed 4 February 2017)

7. Medical and Dental Council of Nigeria. Medical and dental practitioners act CAP M8 http://www.mdenigeria. org/Downloads/Cap\%20M8.pdf (accessed 2 February 2017).

Medical and Dental Council of Nigeria. Guideline on Minimum Standards of Medical and Dental Education in Nigeria. The Red Book. Abuja: MDCN, 2006.

9. McKimm J, Barrow M. Curriculum and course design. Br J Hosp Med 2009;70(12):714-717. https://doi. org/10.12968/hmed.2009.70.12.45510

10. Harden RM, Sowden S, Dunn WR. Educational strategies in curriculum development: The SPICES model. Med Educ 1984;18(4):284-297. https://doi.org/10.1111/j.1365 2923.1984.tb01024.x

1. Goldie J. Review of ethics curricula in undergraduate medical education. Med Educ 2000;34(2):108-119. https://doi.org/10.1046/j.1365-2923.2000.00607.x

12. Gukas ID. Global paradigm shift in medical education: Issues of concern for Africa. Med Teach 2007;29(910):887-892. https://doi.org/10.1080/01421590701814286

13. Norman G. Medical education: Past, present and future. Perspectives Med Educ 2012;1(1):6-14. https://doi. org/10.1007/s40037-012-0002-7

14. Federal Ministry of Health of Nigeria (Health Systems 20/20 Project). Nigeria Undergraduate Medical and Dental Curriculum Template, 2012. Bethesda, Maryland: Abt Associates Inc., 2012.

15. Olopade FE, Adaramoye OA, Raji Y, Fasola AO, Olapade-Olaopa EO. Developing a competency-based medica education curriculum for the core basic medical sciences in an African medical school. Adv Med Educ Pract 2016;7:389-398. https://doi.org/10.2147\%2FAMEP.S100660

16. Kiguli-Malwadde E, Olapade-Olaopa EO, Kiguli S, et al. Competency-based medical education in two sub-Saharan African medical schools. Adv Med Educ Pract 2014;5:483-489. https://doi.org/10.2147\%2FAMEP.S68480

17. Olasoji H. Addressing the issue of faculty development for clinical teachers in Nigeria. Niger J Clin Pract 2014;17(2):265-266. https://doi.org/10.4103/1119-3077.127576

18. Bode C, Ugwu B, Donkor P. Viva voce in postgraduate surgical examinations in Anglophone West Africa. J West Afr Coll Surg 2011;1(1):40-52. https://www.ncbi.nlm.nih.gov/pmc/articles/PMC4170249/ (accessed 31 August 2017)
19. Adeniyi OS, Ogli SA, Ojabo CO, Musa DI. The impact of various assessment parameters on medical student performance in first professional examination in physiology. Niger Med J 2013;54(5):302-305. https://do org $/ 10.4103 \% 2 \mathrm{~F} 0300-1652.122330$

20. Williams BW, Byrne PD, Welindt D, Williams MV. Miller's pyramid and core competency assessment: A study in relationship construct validity. J Contin Educ Health Prof 2016;36(4):295-299. https://doi.org/10.1097/ CEH.0000000000000117

21. Ofoegbu EN, Ozumba BC. Establishment of an office of medical education: Nigeria. Med Educ 2007;41(5):507507. https://doi.org/10.1111/j.1365-2929.2007.02730.x

22. Fahal AH. Medical education in the Sudan: Its strengths and weaknesses. Med Teach 2007;29(9-10):910-914 https://doi.org/10.1080/01421590701812991

23. Albanese MA, Dottl S, Nowacek GA. Offices of research in medical education: Accomplishments and added value contributions. Teach Learn Med 2001;13(4):258-267. https://doi.org/10.1207/S15328015TLM1304_08

24. Kiguli-Malwadde E, Talib ZM, Wohltien H, et al. Medical education departments: A study of four medical schools in Sub-Saharan Africa. BMC Med Educ 2015;15:109. 2-9. https://doi.org/10.1186/s12909-015-0398-y

25. Christopher D, Harte K, George C. The implementation of tomorrow's doctors. Med Educ 2002;36(3):282-288 https://doi.org/10.1046/j.1365-2923.2002.01152.x

26. Al-Wardy NM. Medical education units: History, functions, and organisation. Sultan Qaboos Univ Med 2008;8(2):149-156. https://www.ncbi.nlm.nih.gov/pmc/articles/PMC3074823/ (accessed 3 September 2017).

27. Pritchard LS. Changing course. Med Educ 2004;38(6):584-586. https://doi.org/10.1111/j.1365-2929.2004.01811.

28. Kalaniti K, Campbell DM. Simulation-based medical education: Time for a pedagogical shift. Indian Pediat 2015;52(1):41-45. https://doi.org/10.1007/s13312-015-0565-6

2. Davis MH, Karunathilake I, Harden RM. AMEE Education Guide No. 28: The development and role of departments of medical education. Med Teach 2005;27(8):665-675. https://doi.org/10.1080/0142159050039878

30. Gruppen L. Creating and sustaining centres for medical education research and development. Med Educ 2008;42(2):121-123. https://doi.org/10.1111/j.1365-2923.2007.02931.x

1. Entwistle N. Handbook of Educational Ideas and Practices (Routledge Revivals). Oxon: Taylor \& Francis, 2015.

32. Ventola CL. Mobile devices and apps for health care professionals: Uses and benefits. Pharm Ther 2014;39(5): 356-364. https//www ncbinlm nih gov/pmc/articles/PMC4029126/ (accessed 3 September 2017).

33. Barrow MMI Samarasekera DD. Strategies for planning and designing medical curricula and clinical teaching. South East Asian J Med Educ 2010;4(1):2-8. http://seajme.md.chula.ac.th/articleVol4No1/MedEdP1_Mark\%20 Barrow.pdf (accessed 3 September 2017).

Accepted 5 October 2017. 